\title{
BALTIMOS - a coupled modelling system for the Baltic Sea and its drainage basin
}

\author{
Philip Lorenz • Daniela Jacob
}

Received: 1 September 2014 / Accepted: 7 September 2014

(C) Springer-Verlag Wien 2014

\begin{abstract}
The major tasks of the Baltic Sea Experiment (BALTEX) are to simulate the water and energy cycles of the Baltic Sea catchment and to identify important processes, which are relevant to the climate in the Baltic region. A fully coupled regional climate model system for the Baltic Sea region, called BALTIMOS, was developed in the framework of the German climate research program DEKLIM by linking existing model components for the atmosphere, for the ocean including sea ice, and for hydrology. With this system, it is possible to model the complete water and energy cycles for the Baltic Sea catchment for today's climate, as well as for the future with climate scenarios. The emphasis in this paper is given to the description of the modelling system and on the comparison of the results of the fully coupled BALTIMOS system against the results of the uncoupled atmospheric component REMO for today's climate. Both simulations are driven at the atmospheric lateral boundaries with ECMWF analysis data from the European Centre for Medium Range Weather Forecast (ECMWF) for 5 years each. In the uncoupled run, the sea surface temperature (SST) and ice surface temperature (IST) analysed by ECMWF are prescribed, while in the coupled run, SST and IST are provided by the ocean/sea ice model BSIOM. Several analysed parameters are very similar for the land part of the Baltic Sea catchment, while there are differences especially for surface and near-surface temperatures for the fraction of the Baltic Sea itself that indicate
\end{abstract}

Submitted to "Theoretical and Applied Climatology" for inclusion into the "BALTIMOS" special issue.

P. Lorenz $\cdot$ D. Jacob

Max Planck Institute for Meteorology, Bundesstr. 53, Hamburg, Germany

P. Lorenz $(\bowtie)$

Freie Universität Berlin, Institute of Meteorology,

Carl-Heinrich-Becker-Weg 6-10, Berlin, Germany

e-mail:Philip.Lorenz@fu-berlin.de further research efforts. As no corrections for the modelled air-sea fluxes are applied for the coupled model system, it is a good result that no drift of the coupled model system is visible in the 5-year integration. The present paper gives an overview about the development of the coupled model system and shows results from first integrations of the system.

\section{Introduction}

The Baltic Sea is a relatively enclosed waterbody located in Northern Europe in the west wind zone of the mid-latitudes, only connected to the Northern Sea at its western boundary. The climate in the region is therefore dominated by northern hemispheric pressure systems travelling from west to east, but is also largely influenced by the water body of the Baltic Sea itself and its surrounding land surface. The northern parts of the Baltic Sea are usually covered by sea ice during winters, which is an important characteristic of the climate in this region.

Rising observed near-surface temperatures in nearly all regions of the globe give evidence for an anthropogenic change of the climate. For Europe, an increase of near-surface temperatures of about $0.8 \mathrm{~K}$ was observed for the twentieth century (Jones and Moberg 2003). Understandably, the need for information about possible future changes of the climate is obvious.

High spatial and temporal resolutions are desired for regional climate change information, which can be gained by downscaling of global climate change information using regional climate models (RCMs). RCMs act not globally, but with high spatial and temporal resolutions on a specific region, using output of global climate models (GCMs) for getting information at the lateral boundaries of their simulation domain.

In the context of global climate models, coupled atmosphere-ocean-hydrology models are state of the art (IPCC 2007). However, up to now, only a few regional coupled atmosphere-ocean model systems are available (e.g. 
Rinke et al. 2003; Döscher et al. 2002; Mikolajewicz et al. 2005). The Baltic Sea region is certainly a region where the application of such coupled regional model systems seems to be necessary when downscaling coupled global climate model (CGCM) results: In state-of-the-art CGCMs, the Baltic Sea consists only of a few grid points. The Baltic Sea is a waterbody with complex topography; the connection to the North Sea by Kattegat and Skagerrak plays an important role, which is not at all resolved by CGCMs. Therefore, it is very likely that the simulated sea surface temperatures for the Baltic Sea have large errors in CGCMs experiments. As this erroneous sea surface temperature (SST) data would act in an atmospheric RCM as lower boundary condition, the simulation would be affected by the poorly resolved SST from CGCM in the Baltic Sea region. In contrast, within a coupled regional climate model system, the ocean component would simulate a more realistic SST distribution, and therefore, the results in the Baltic Sea region would be improved. Thus, it is obvious that coupled regional ocean/atmosphere/sea ice models represent a major element in the BALTEX strategy of assessing the energy budget and water cycle in the Baltic Sea catchment area. The Swedish Meteorological and Hydrological Institute (SMHI) has set up the first coupled regional model system for the Baltic Sea (Rummukainen et al. 2001; Döscher et al. 2002) showing considerable improvements.

Within the German Climate Research programme DEKLIM, the BALTIMOS project was funded in order to develop and validate a coupled regional climate model system for the Baltic Sea region. BALTIMOS was coordinated by the Max Planck Institute for Meteorology (MPI-M). While most of the nine BALTIMOS partner institutions dealt with the validation of the coupled model system, MPI-M had the task to setup the coupled regional model system.

The present paper gives an overview about the development of the coupled model system and shows results from first integrations of the system. The paper is structured as follows: First, a technical description of the coupled regional model system is given. In the following chapter, the conducted experiments and used data sets are introduced. Then, the results of the comparisons are presented. Finally, conclusions are derived.

\section{Technical description of the coupled regional model system BALTIMOS}

\subsection{BALTIMOS components}

Existing state-of-the-art model components for the atmosphere, for the ocean including sea ice and for the terrestrial hydrology built the basis for the setup of the coupled regional model system for the Baltic Sea region, called BALTIMOS: The regional climate model REMO is used for the atmosphere, the Baltic ocean/sea ice model BSIOM for the ocean and sea ice and LARSIM for the terrestrial hydrology. Each of the three model components have been used extensively before in an uncoupled mode for climate studies within several projects; they are all well validated (e.g. Hennemuth and Jacob 2002; Hagemann et al. 2002; Lehmann et al. 2002; Rudolph and Lehmann 2006; Richter and Ebel 2006).

The individual components and their setup used in BALTIMOS will be introduced in the following sub-sections:

\subsubsection{The regional atmospheric climate model REMO}

REMO is a hydrostatic three-dimensional atmospheric regional climate model (Jacob 2001). It is based on the former numerical weather prediction system of the German Weather Service (DWD), the so-called EM/DM system. The set of physical parameterizations has been absorbed from the global climate model ECHAM4.

Fractions of land, open water and sea ice are assigned to each grid box. REMO treats momentum and energy fluxes as well as temperatures at the surface for each of these three surface types separately.

REMO is applied in BALTIMOS on a domain covering Northern Europe, with the Baltic Sea catchment in its centre. REMO uses a rotated coordinate system in a horizontal resolution of $1 / 6^{\circ}$ (approximately $18 \mathrm{~km}$ ) with $121 \times 181$ grid points and 20 vertical levels (see Fig. 1).

\subsubsection{The Baltic ocean/sea ice model BSIOM}

The Baltic Sea Ice/Ocean Model (BSIOM) is a threedimensional baroclinic ocean model for the Baltic Sea (Lehmann 1995), internally coupled to a dynamic thermodynamic sea ice model (Lehmann and Hinrichsen 2000). The horizontal resolution of the ocean model is about $5 \mathrm{~km}$, and the computational domain consists of $239 \times 269$ grid points on a non-rotated geographical grid, which is not identical to the grid used by the atmospheric and hydrological modules. In the vertical, up to 60 levels are used depending on the depth of the Baltic Sea at the respective grid point. At 42 positions along the coast, corresponding to the major rivers flowing into the Baltic Sea, values for freshwater inflow into the Baltic Sea are prescribed. The computation domain covers the whole Baltic Sea and partly the North Sea (see Fig. 2). In the part of the North Sea, a relaxation is applied for sea surface temperature (SST) and for surface salinity.

\subsubsection{The hydrological model LARSIM}

The hydrological model LARSIM (Bremicker 2000) has been developed during the first phase of BALTEX with respect to the climate models REMO and ECHAM4; thus, the vertical 
Fig. 1 Computational domain for REMO $(121 \times 181$ grid points on a $1 / 6^{\circ}$ rotated grid) with Baltic

Sea catchment (red line)
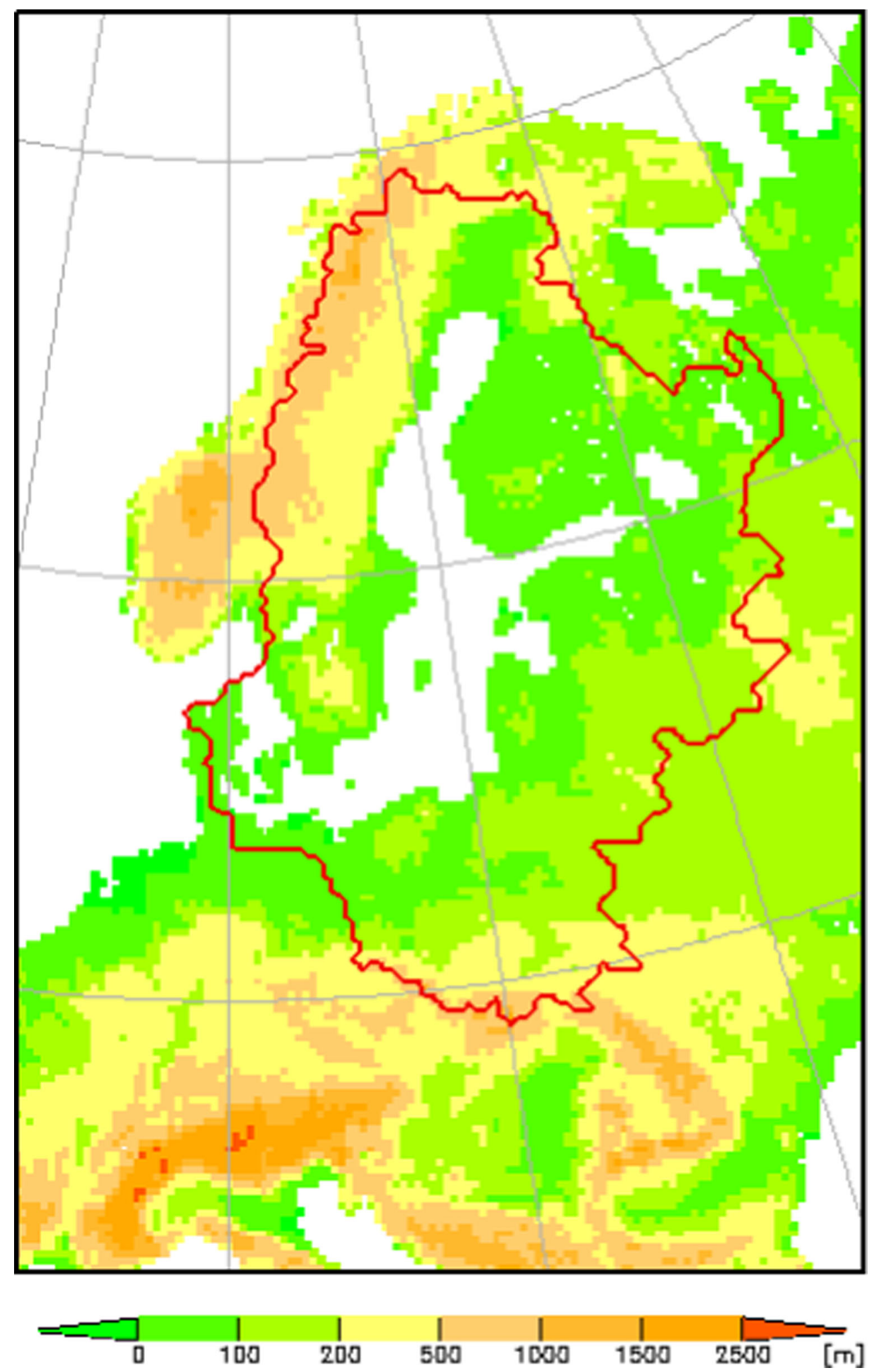

soil scheme is identical in REMO and LARSIM. Especially, both modules use two components for the description of total runoff, namely, the water which runs off at the surface (surface runoff), and the infiltrated water which runs off within the soil drainage (drainage).
Therefore, from a technical point of view, in BALTIMOS, the vertical soil processes like generation of runoff are computed within REMO, while the coupled LARSIM module represents the river routing scheme, which is not part of REMO. 
Fig. 2 Topography of the BSIOM ocean/sea ice model. Red crosses mark the coastal grid boxes with freshwater input
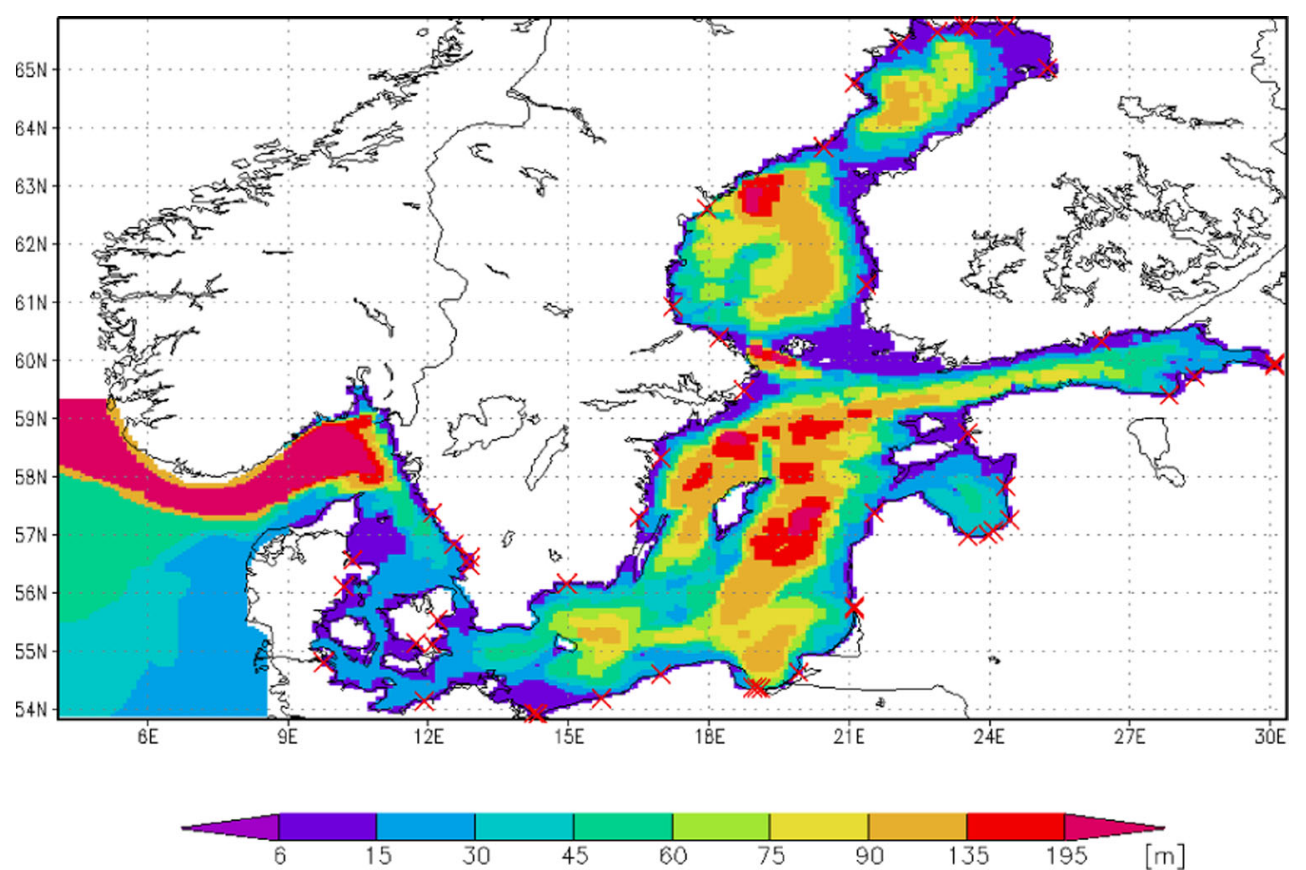

The river routing scheme of LARSIM works on the same horizontal grid as REMO and with an internal time step of $1 \mathrm{~h}$.

The scheme routes the two runoff components through a river network. The river routing scheme has been set up for the whole land part of Baltic Sea catchment area and ends in 42 points at the coast of the Baltic Sea, which correspond exactly to the 42 coastal positions on which the freshwater inflow can be described within the ocean module BSIOM. The river routing scheme is shown in Fig. 3.

\subsection{Coupling}

For the setup of the coupled regional modelling system, a coupling procedure has been developed and implemented. A schematic overview over the coupling components and their coupling variables is given in Fig. 4. Common to all interfaces is the coupling time step of $1 \mathrm{~h}$. Furthermore, it should be stressed that no flux corrections are applied in any interface.

The interfaces between the individual model components are described in the following sub-sections.

\subsubsection{Atmosphere-ocean/sea ice}

The coupling between the atmospheric model REMO and the ocean/sea ice model BSIOM is based on the work of Hagedorn et al. (2000), where REMO has been coupled with the ocean component of the BSIOM without a sea ice component. For the coupling between the atmospheric (REMO) and the oceanographic (BSIOM) component, surface fluxes for momentum (vector components of surface wind stress) and heat (longwave and shortwave radiation, sensible and latent heat flux) are computed by REMO for the ice-free (open water) part and for the ice-covered part of each REMO grid box in the area of the Baltic Sea. These values as well as mean sea level surface pressure (MSLP) are computed for each REMO internal time step (120 s); they are averaged at the end of each 1-h coupling interval. Due to the mismatching grids of REMO and BSIOM, the flux values and MSLP as well as accumulated 1-h total precipitation are interpolated by a bilinear interpolation from the rotated REMO grid $(\sim 18 \mathrm{~km})$ to the non-rotated and finer $(\sim 5 \mathrm{~km})$ grid of the BSIOM model. Finally, all interpolated fields are passed to BSIOM. BSIOM is integrated then for the duration of one coupling interval (1 h) using the computed fields from REMO as upper boundaries. BSIOM returns fractional sea ice cover together with surface temperatures (sea surface temperature (SST) for open water parts and ice surface temperature for ice-covered parts) valid for the end of the corresponding coupling interval. Due to the mismatching grids of BSIOM and REMO, these three fields have to be aggregated from the BSIOM grid the coarser REMO grid before returning them to REMO. In REMO, these fields are updated by the returned fields within the area of the Baltic Sea. In other sea areas outside the Baltic Sea, the treatment is identical to an uncoupled REMO simulation, i.e. SST and sea ice fraction are prescribed. After the update, REMO continues until the next coupling interval.

\subsubsection{Atmosphere-lateral discharge module}

Within the vertical soil module of REMO, runoff is computed for every REMO internal time step at each land grid box. The 
Fig. 3 LARSIM river routing scheme for the whole Baltic Sea catchment (upper part) and zoomed to the catchment of the Daugava river

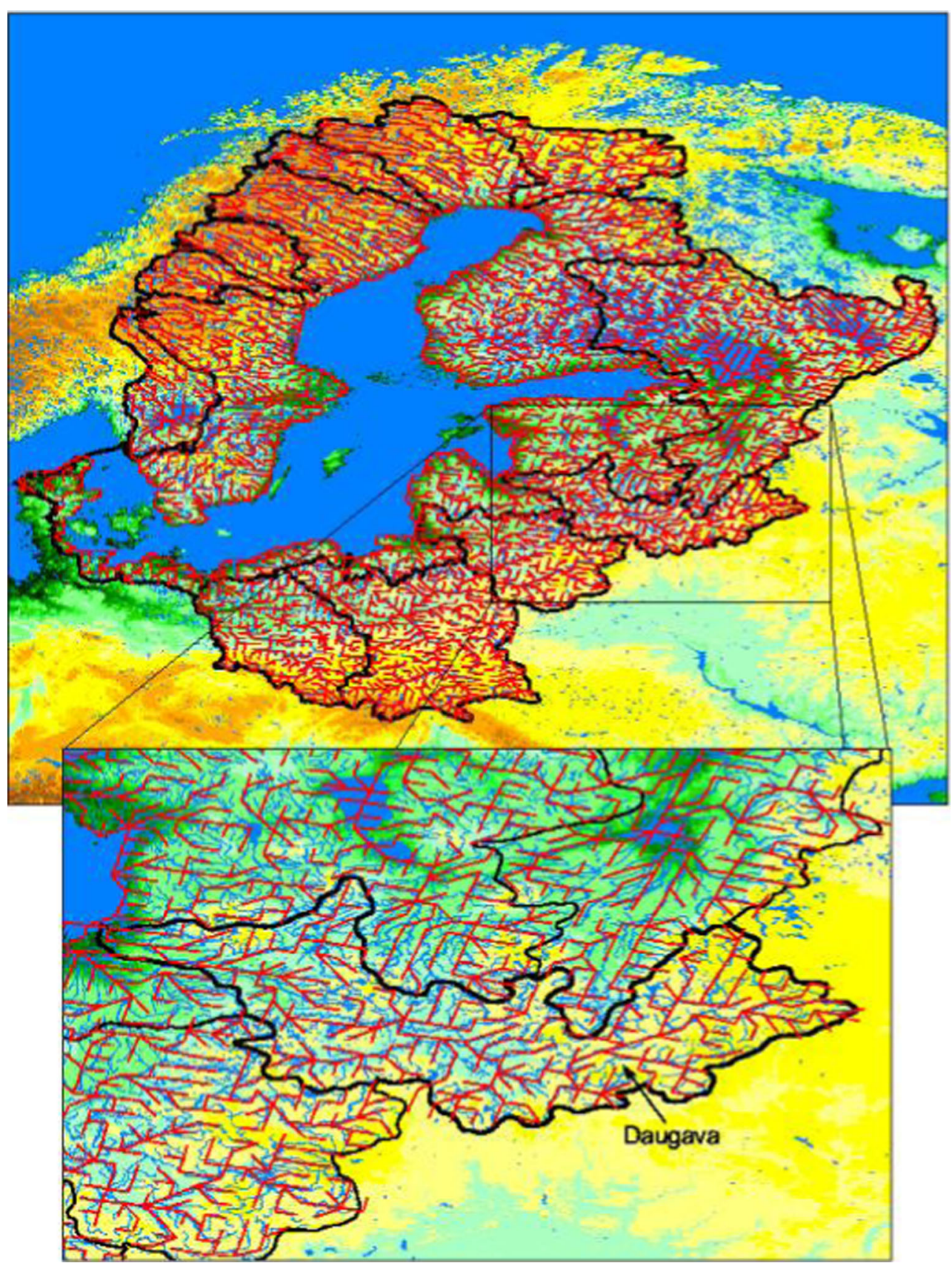

runoff is calculated for two components surface runoff and drainage. These values are accumulated during each coupling interval of $1 \mathrm{~h}$ and then passed to the lateral routing scheme of LARSIM. There is no feedback from the routing scheme to REMO.

\subsubsection{Lateral discharge module-ocean/sea ice module}

At the 42 ending points of the LARSIM river routing scheme, the computed amounts of river discharge for the coupling interval of $1 \mathrm{~h}$ are passed as freshwater input into the BSIOM model.

\section{Experiments and data}

\subsection{Meteorological data from SMHI}

For validation purposes, a meteorological gridded data set provided by the BALTEX Hydrological Data Centre (BHDC) at SMHI has been used for comparison with the model simulations. It is briefly described in Omstedt et al. (1997). The data set is based on data from all available synoptic weather stations. The station measurements were interpolated in space using a two-dimensional univariate optimum interpolation scheme. The data set has a horizontal 
Fig. 4 Schematic overview over the coupling components and their coupling variables

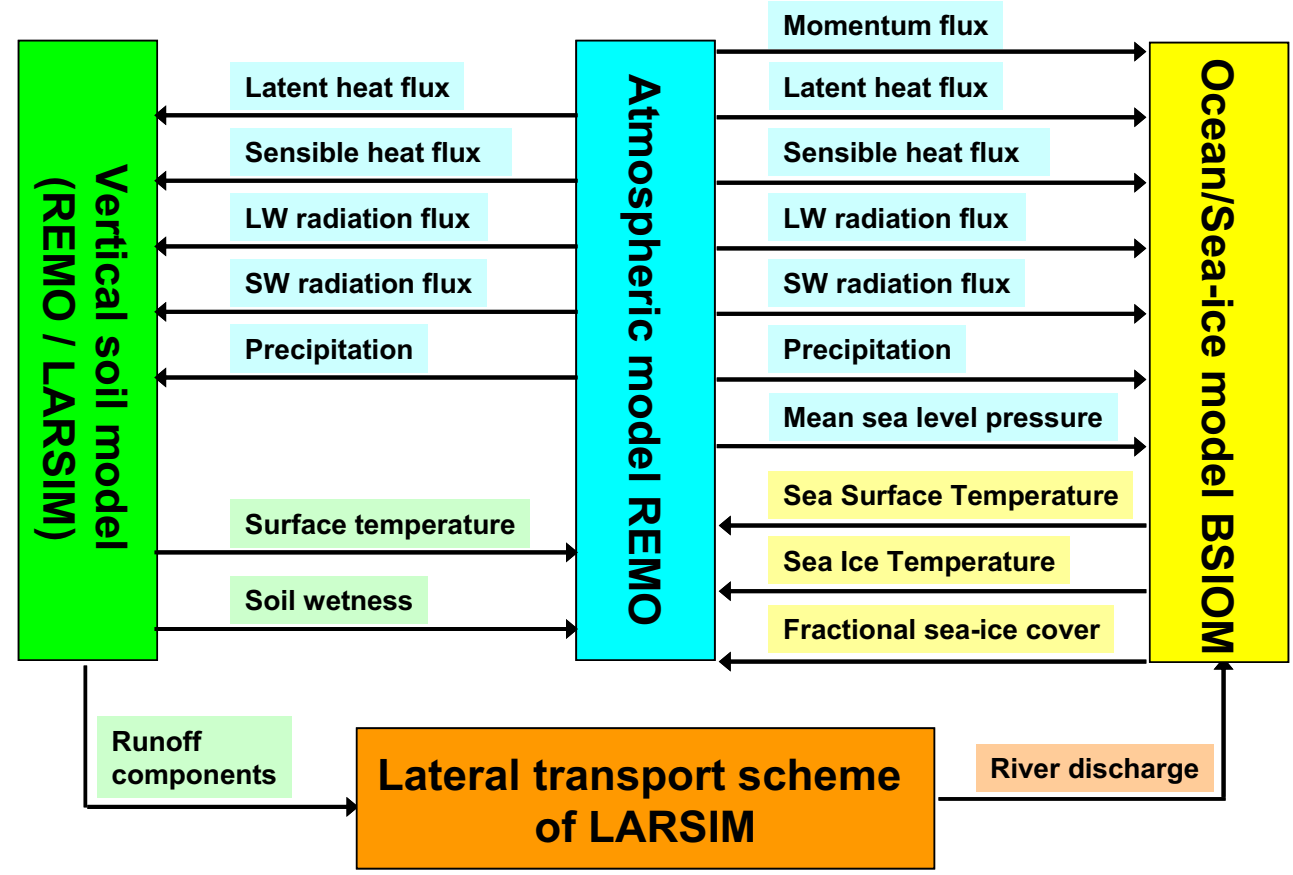

resolution of $1^{\circ} \times 1^{\circ}$ and a temporal resolution of $3 \mathrm{~h}$ and includes mean sea level pressure (MSLP), geostrophic wind components, 2-m temperature, relative humidity $(2 \mathrm{~m})$, total cloud cover and precipitation (12 hourly). It is available for the period from 1970 onwards and is continuously updated with a delay of about 6 months.

It should be noted that in this data set no correction for systematic undercatch in precipitation data is applied. The quality of the data set is after Omstedt et al. (2004) comparable with the ERA40 data set from European Centre for Medium Range Weather Forecast (ECMWF).

For the comparison of model results with this data set, the model fields were aggregated to the grid of this data set.

\subsection{Simulations with the BALTIMOS system}

Two simulations with different configurations of the BALTIMOS system have been carried out and compared against each other and against observations.

First, a 5-year simulation for present day climate (19992003) has been carried out with the fully coupled modelling system (in the following called BALTIMOS-RBL or 'coupled'). In order to avoid a too large ratio of the horizontal resolution of the driving data fields to the horizontal resolution of the RCM, a so-called double-nesting procedure has been used: Initialization and lateral boundary data (and SST data for ocean surfaces outside the Baltic Sea) for the atmospheric component were taken from an uncoupled REMO run in coarser resolution $\left(0.5^{\circ}\right)$ covering a significantly larger domain (Europe). The coarser REMO run was initialized and driven at the lateral boundaries and at the lower boundaries over sea areas for sea surface temperatures (SSTs) using analysis data from the European Centre for Medium Range Weather Forecast (ECMWF). The ocean model (BSIOM) was initialized by taking results from an uncoupled BSIOM run, which was driven at its upper boundary by the gridded meteorological variables from the SMHI data set described above. Surface fluxes were calculated from the atmospheric variables using bulk aerodynamic formulas. This uncoupled initialization run was continuously integrated from the years 1970 until 1999 in order to provide steady state three-dimensional temperature and salinity fields for the water body of the Baltic Sea.

Second, an uncoupled model simulation with the atmospheric component REMO (in the following called BALTIMOS-R or 'uncoupled') has been integrated for the same period (1999-2003). It was initialized and driven at the lateral boundaries and lower boundaries over sea (SST and sea ice fraction) using the same double-nesting procedure as in the coupled experiment.

\section{Results}

\subsection{Mean sea level pressure}

The mean sea level pressure (MSLP) is a quantity which mirrors the large-scale atmospheric state. Figure 5 shows the 
Fig. 5 Time series (running 7day mean) of mean sea level pressure (MSLP, hPa). Black lines show the uncoupled BALTIMOS-R simulation, red lines the coupled BALTIMOSRBL and blue lines the gridded meteorological data set from SMHI. The upper panel shows area mean values for the land part of the catchment, and the lower panel for the water part of the catchment, the Baltic Sea itself
BALTEX Land
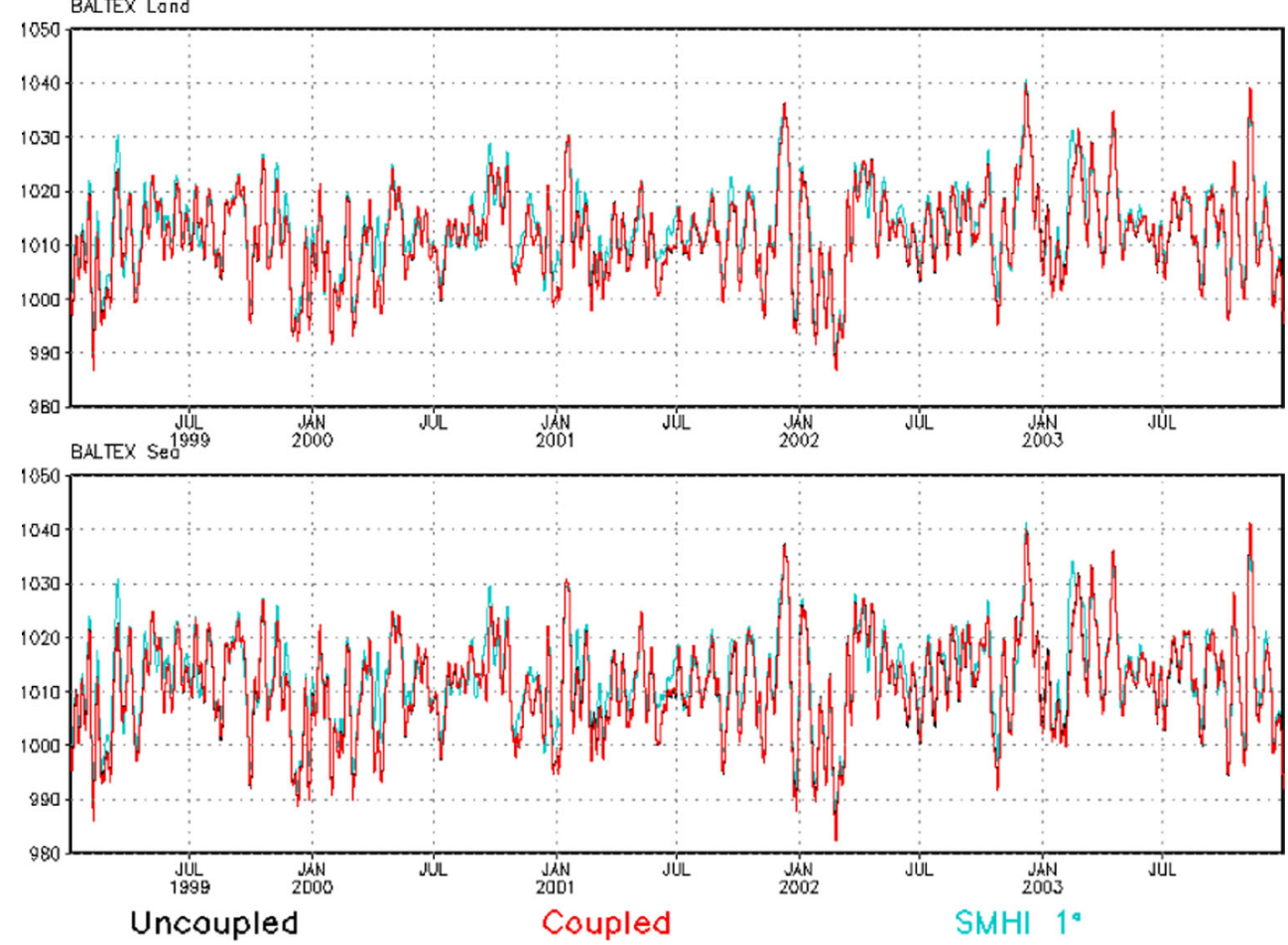

temporal evolution of MSLP over the catchment of the Baltic Sea. The black lines in all panels showing the results of the uncoupled simulation are almost not visible, because they are overlaid by the red lines of the coupled experiment. This means that the evolution of MSLP, and therefore of the general dynamic development in the atmosphere, is very similar in both experiments. As both experiments are forced in the atmosphere with the same lateral boundary data, this behaviour is expected.

Furthermore, the simulations show a quite good agreement to the meteorological SMHI data set. As the lateral boundary data came from analysis data, so-called
Fig. 6 Time series (running 7day mean) of 2-m temperature $\left({ }^{\circ} \mathrm{C}\right)$. Black lines show the uncoupled BALTIMOS-R simulation, red lines the coupled BALTIMOS-RBL and blue lines the gridded meteorological data set from SMHI. The upper panel shows area mean values for the land part of the catchment, and the lower panel for the water part of the catchment, the Baltic Sea itself
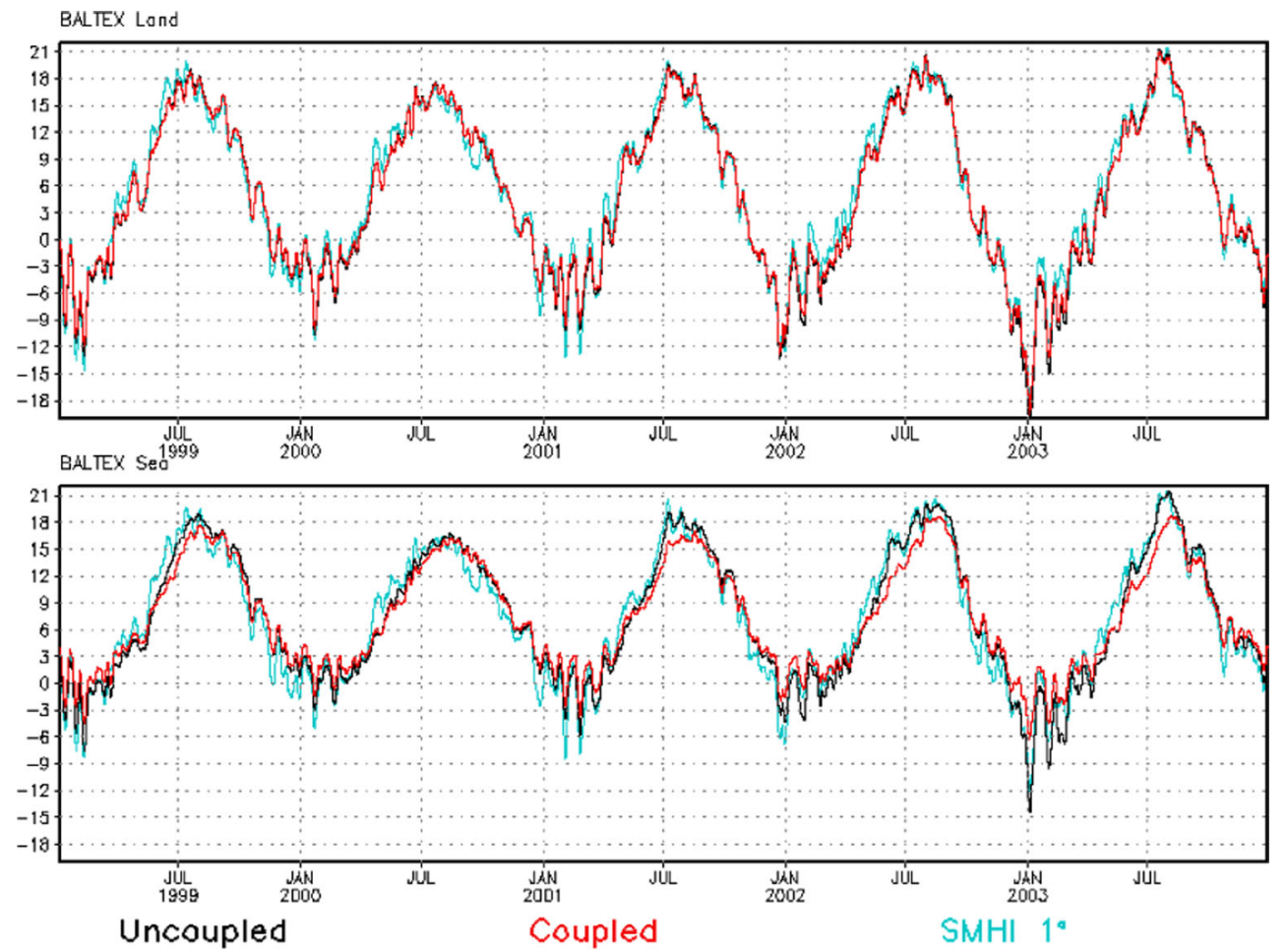
Table 1 Mean seasonal and annual near-surface $(2 \mathrm{~m})$ temperatures $\left({ }^{\circ} \mathrm{C}\right)$ for the land part (water part) of the Baltic Sea drainage basin on the left (right) side; in each case for the meteorological data set from SMHI, and for the uncoupled and coupled BALTIMOS experiments

\begin{tabular}{|c|c|c|c|c|c|c|}
\hline & \multicolumn{3}{|c|}{ Land fraction } & \multicolumn{3}{|l|}{ Sea fraction } \\
\hline & SMHI data & Uncoupled & Coupled & SMHI data & Uncoupled & Coupled \\
\hline MAM & 4.75 & 3.39 & 3.56 & 5.17 & 3.68 & 4.32 \\
\hline JJA & 16.07 & 16.06 & 15.87 & 16.34 & 16.15 & 14.51 \\
\hline SON & 5.54 & 6.01 & 6.01 & 8.23 & 9.76 & 9.60 \\
\hline DJF & -4.87 & -5.86 & -5.29 & -0.92 & -0.62 & 1.26 \\
\hline Annual & 5.43 & 5.00 & 5.13 & 7.25 & 7.30 & 7.45 \\
\hline
\end{tabular}

Values are the means of 5 seasons/years (4 seasons for DJF) for the years 1999-2003

SMHI Swedish Meteorological and Hydrological Institute

'perfect boundaries', it is expected that there is a good agreement to observations.

\subsection{Near-surface temperature}

Figure 6 shows the temporal evolution of 2-m temperature within the Baltic Sea catchment for the simulations and the observational data set. Mean seasonal as well as mean annual values for the years 1999-2003 are given in Table 1. Over the land part of the catchment, the evolution between the uncoupled and coupled experiment is very similar and in general in good agreement with the meteorological data set from SMHI with the exception of the spring season, where the modelled temperatures are in general slightly lower than in the observations (about $1.3 \mathrm{~K}$ ).

Over the Baltic Sea itself, there are major deviations between the coupled and the uncoupled BALTIMOS runs: From around April to August, there are lower temperatures in the

Fig. 7 Seasonal mean surface temperature for winter (DJF) 2001/2002 coupled experiment than in the uncoupled one, and from October to March, there are higher temperatures in the coupled experiment, with the highest deviations in winter. Mean summer-JJA (winter-DJF) values of near surface temperature for the area of the Baltic Sea are $16.1^{\circ} \mathrm{C}\left(-0.6^{\circ} \mathrm{C}\right)$ in the uncoupled run and $14.5^{\circ} \mathrm{C}\left(1.3^{\circ} \mathrm{C}\right)$ in the coupled run. In other words, the amplitude of the annual cycle of 2-m temperature is reduced, and its phase is delayed by some weeks in the coupled run with respect to the uncoupled run. It should be noted here that no systematic trend is visible in the simulations.

The supposed cause for the differences in 2-m temperature between the coupled experiment and the uncoupled one can be found in the analysis of the modelled SST, which affects strongly the temperatures in $2-\mathrm{m}$ height. Wintertime (summertime) SST is, in the coupled experiment, significantly higher (lower) than in the uncoupled experiment (Fig. 7 shows an example for the winter season 2001/2002).
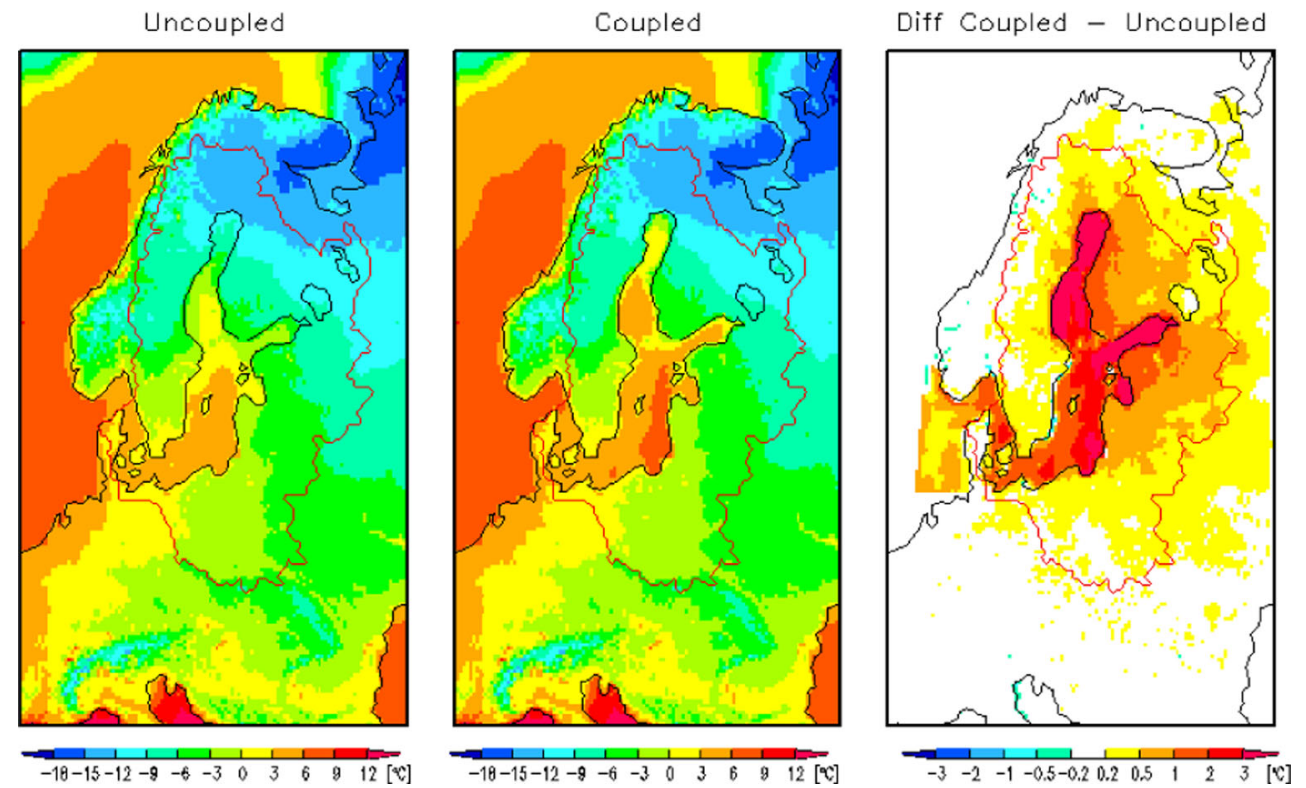
Fig. 8 Temporal evolution of the fractional sea ice cover of the Baltic Sea in the uncoupled BALTIMOS-R simulation (black line) and in the coupled BALTIMOS-RBL simulation (red line)

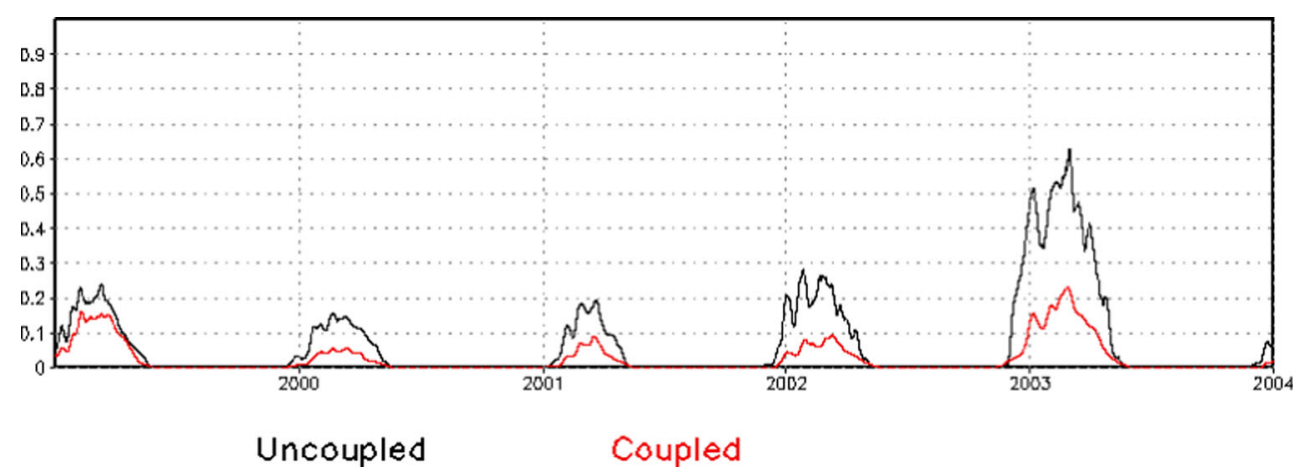

Uncoupled
Coupled
In Bennartz et al. (2009), SSTs over open water in the coupled BALTIMOS experiment were compared against satellite-derived observations (AMSR-E). They found that in the coupled BALTIMOS run, the annual cycle is slightly delayed and its amplitude is reduced with respect to the observations. The differences are similar to the differences between the uncoupled and coupled BALTIMOS 2-m temperatures found in the present study. This leads to the conclusion that SSTs (and therefore presumably also near-surface temperatures over sea) are more realistic in the uncoupled than in the coupled experiment.

The more realistic simulation of near surface temperatures over the Baltic Sea in the uncoupled experiment is also supported by the comparison against the meteorological data set from SMHI (Fig. 6): Over sea, the uncoupled run shows a much better agreement with this data set than the coupled experiment especially during summer and winter, but during spring (autumn), both model runs show lower (higher) temperatures than the observational data set from SMHI (see Table 1). As mentioned above, in spring, there are also lower temperatures in both model runs over the land part of the catchment, but the deviations over the Baltic Sea itself are larger. This behaviour could point to a problem in the SMHI data set over the sea fraction: As this gridded data set has been derived from land station measurements, its phase of the annual cycle over sea surfaces is also influenced by the phase of the annual cycle over land. Because of the larger heat uptake of the ocean due to vertical mixing within the water body compared to soil on land, the surrounding land is heating up faster during spring as the water of the Baltic Sea, and is cooling down faster during autumn. So the phase of the annual cycle over sea is delayed with respect to the phase over land, which could lead to a premature phase of near surface temperatures over water areas in the gridded SMHI data set. This was first addressed by Omstedt and Axell (2003) where correction methods were developed for air temperature and wind speed.

In conclusion, the annual cycle of 2-m temperatures and SST over sea is more realistic in the uncoupled than in the coupled experiment.

\subsection{Sea ice coverage, temperature and thickness}

Figure 8 shows the temporal evolution of fractional sea ice cover in the simulations. Clearly, the coupled experiment shows lower amounts of fractional sea ice cover, which is mostly caused by the higher winter ocean surface temperatures in the coupled experiment. The onset date of ice growing occurs slightly later in the coupled experiment; the offset date in contrast agrees quite well between both experiments. A comparison with satellite-derived sea ice coverage (Bennartz et al. 2009) shows that the coupled experiment has much lower sea ice extent than derived from satellite data. Therefore, the sea ice extent in the uncoupled run seems to be more realistic.

Figure 9 shows as an example the temporal evolution of sea ice surface temperature (IST) for winter 2001/2002 (for the comparison only those grid cells, in which both the coupled

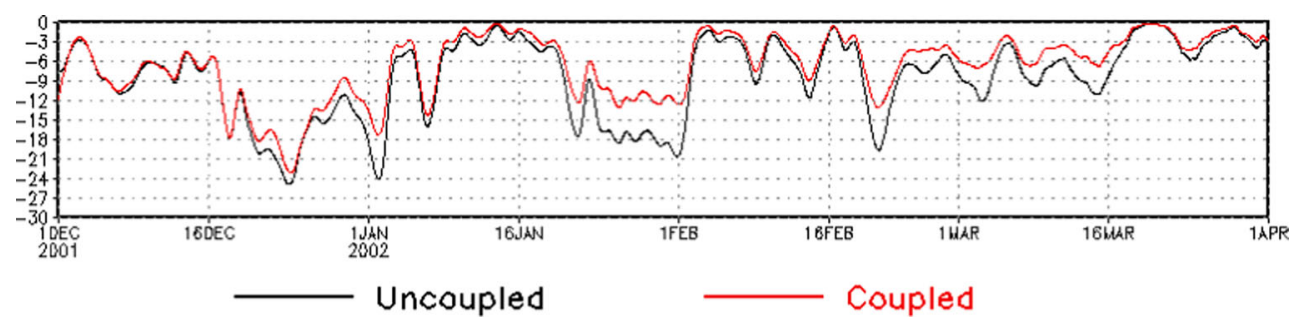

Fig. 9 Temporal evolution of sea ice surface temperature for December 2001 to March 2002 in the uncoupled BALTIMOS-R simulation (black line) and in the coupled BALTIMOS-RBL simulation (red line). For both curves, only grid boxes were considered, where both simulations have a sea ice fraction greater than $10 \%$ 
Fig. 10 Sea ice thickness at 1 st of March 2003 in the coupled BALTIMOS simulation (left). Sea ice concentration at 1st of March 2003 derived from AMSR-E satellite data (right)

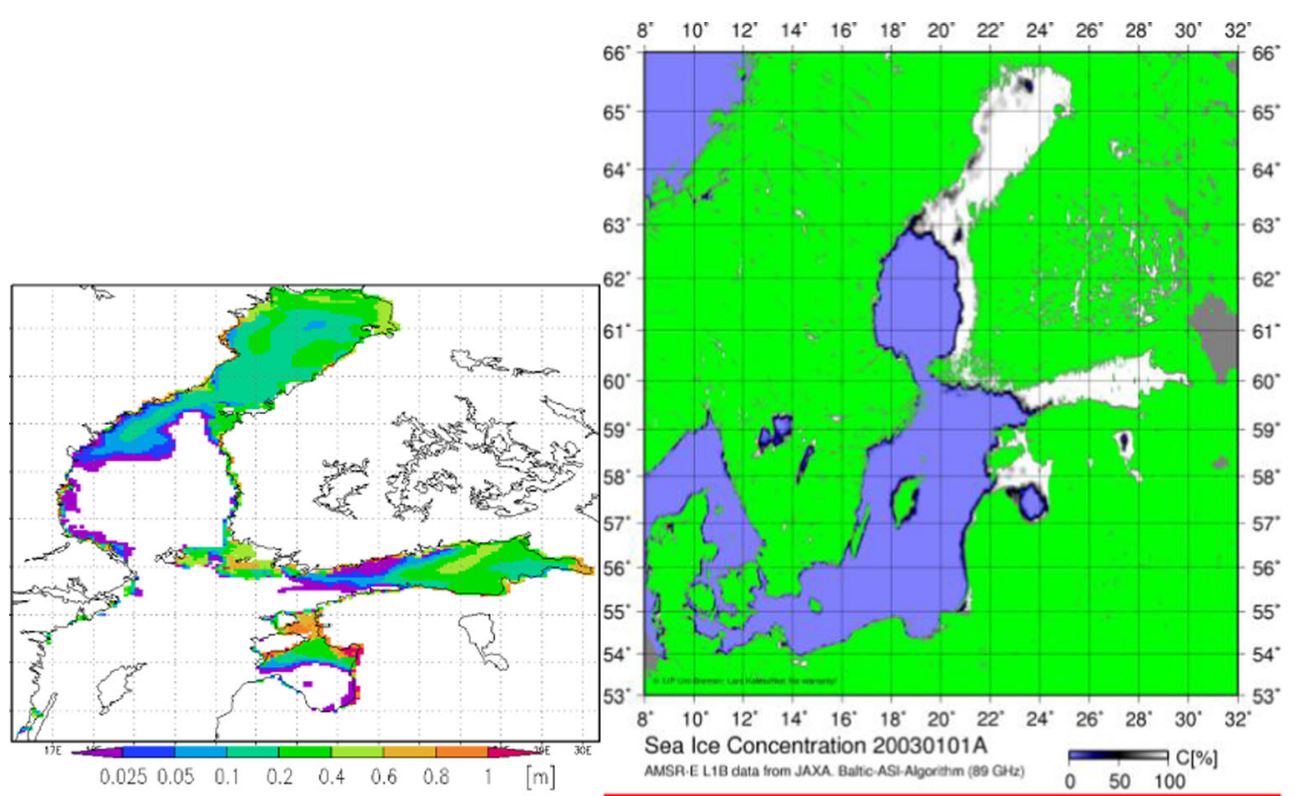

and the uncoupled simulations have a sea ice fraction greater than $10 \%$ each): There is a very high temporal correlation of IST in both runs indicating a very similar sequence of weather conditions. Nevertheless the variability in IST is larger in the uncoupled experiment reaching significantly lower (temporally up to $8 \mathrm{~K}$ ) IST values and shows colder temporal mean IST. These strong temperature deviations over the ice-covered areas are partly responsible for the high wintertime $2-\mathrm{m}$ temperature deviations discussed in the previous section. The deviations in IST might partly be explained by the fact that the uncoupled model prognoses IST using a fixed sea ice thickness of $2 \mathrm{~m}$, which certainly is too high for the Baltic Sea with relatively thin sea ice. Due to the fact that sea ice has relatively low heat conductivity, this would explain the large variability in IST in the uncoupled experiment. In the coupled run, the sea ice thickness is not a constant value but varies with space and time. Figure 10 shows as an example the sea ice thickness at 1st of March 2003 in the coupled simulation in
Fig. 11 Time series (running 7day mean) of total precipitation ( $\mathrm{mm} /$ day). Black lines show the uncoupled BALTIMOS-R simulation, red lines the coupled BALTIMOS-RBL and blue lines the gridded meteorological data set from SMHI. The upper panel shows area mean values for the land part of the catchment, and the lower panel for the water part of the catchment, the Baltic Sea itself
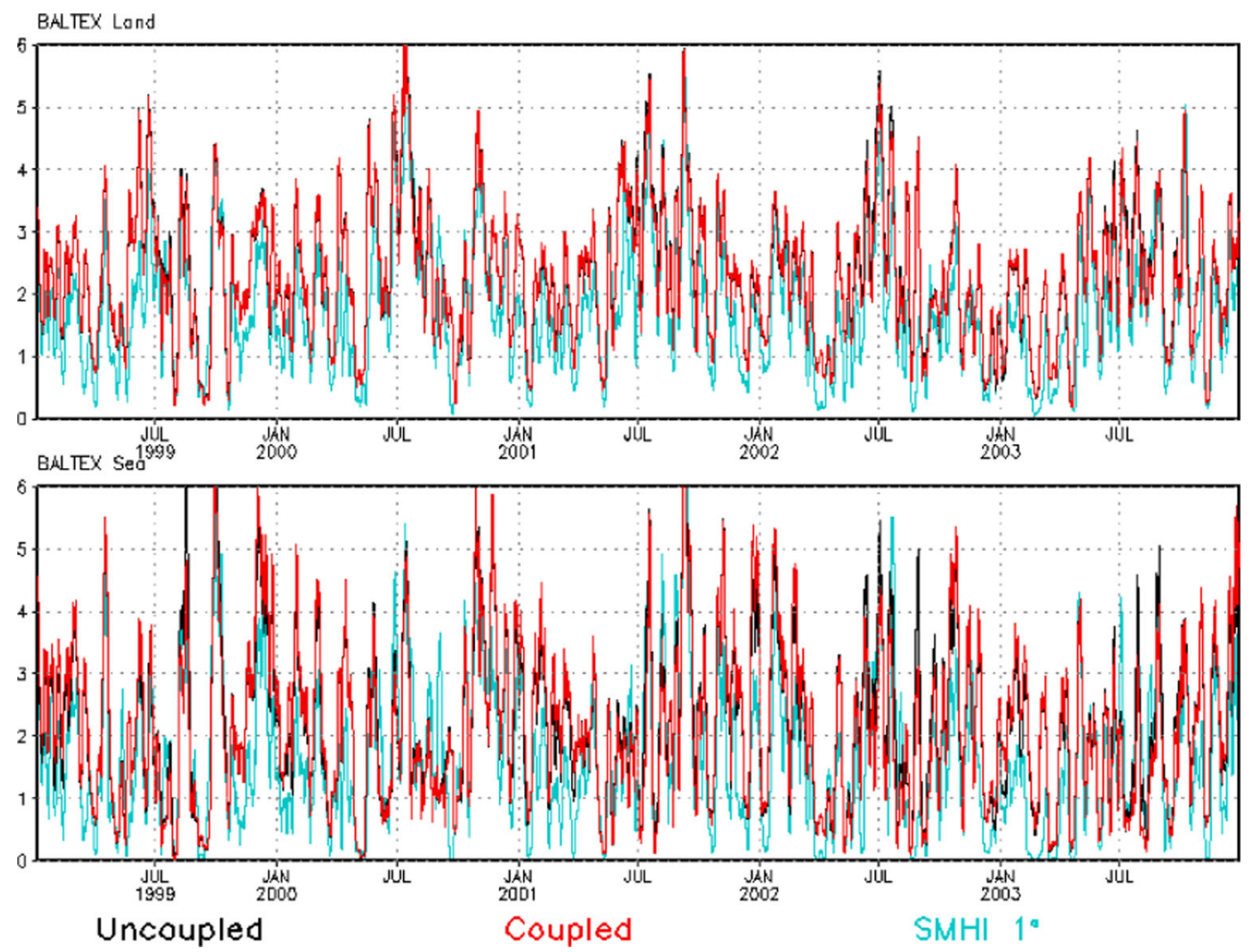
Table 2 Mean seasonal and annual precipitation sums ( $\mathrm{mm} /$ day) for the land part (water part) of the Baltic Sea drainage basin on the left (right) side; in each case for the meteorological data set from SMHI, and for the uncoupled and coupled BALTIMOS experiments

\begin{tabular}{|c|c|c|c|c|c|c|}
\hline & \multicolumn{3}{|c|}{ Land fraction } & \multicolumn{3}{|l|}{ Sea fraction } \\
\hline & SMHI data & Uncoupled & Coupled & SMHI data & Uncoupled & Coupled \\
\hline MAM & 1.33 & 1.99 & 2.00 & 1.17 & 1.72 & 1.75 \\
\hline JJA & 2.39 & 3.04 & 2.93 & 1.99 & 2.07 & 1.78 \\
\hline SON & 1.79 & 2.18 & 2.17 & 1.90 & 2.49 & 2.46 \\
\hline DJF & 1.44 & 1.98 & 2.01 & 1.47 & 2.34 & 2.60 \\
\hline Annual & 1.75 & 2.31 & 2.29 & 1.65 & 2.17 & 2.17 \\
\hline
\end{tabular}

Values are the means of 5 seasons/years (4 seasons for DJF) for the years 1999-2003

SMHI Swedish Meteorological and Hydrological Institute

comparison with a satellite (AMSR-E) derived sea ice concentration. Here the values for sea ice thickness vary between 0 and $1 \mathrm{~m}$, which seems to be rather realistic for the Baltic Sea (Haapala and Leppäranta 1997). Furthermore, there is an overall good agreement with the sea ice concentration derived by AMSR-E.

\subsection{Precipitation}

Figure 11 shows the temporal evolution of total precipitation, and Table 2 the mean seasonal and annual values for 1999 2003. Again, there is a very high correlation between the coupled and the uncoupled experiment, but now stronger differences are visible. This is especially true for the sea part of the catchment, where differences in surface temperatures are influencing the processes leading to precipitation. But, also in the land area, where temperatures are very similar, there are some deviations. This reflects the fact that precipitation is a parameter which is very sensitive to small changes of the atmospheric conditions. Compared to the SMHI data set, in the overall mean, there is more precipitation in the BALTIMOS simulations: For the land fraction (water fraction), the annual mean of precipitation is $1.75(1.65) \mathrm{mm} /$ day in the SMHI data set, $2.31(2.17) \mathrm{mm} /$ day in the uncoupled run and $2.29(2.17) \mathrm{mm} /$ day in the coupled run. Partly, this can be attributed to the fact, that the SMHI data set is not corrected for systematic undercatch in precipitation measurements (rain drops and snow particles are drifting partly around the rain gauge due to winds, which leads to an underestimation of precipitation in the measurements; Forland and Hansson-Bauer 2000). This seems to be plausible, as the higher precipitation values in BALTIMOS appear predominantly during the winter seasons, when the undercatch could be strongest due to high wind velocities and precipitation in the form of snow particles, for which the systematic undercatch is in general stronger than for rain drops.
Fig. 12 Total precipitation $(\mathrm{mm} /$ day) for the winter season 2001/2002

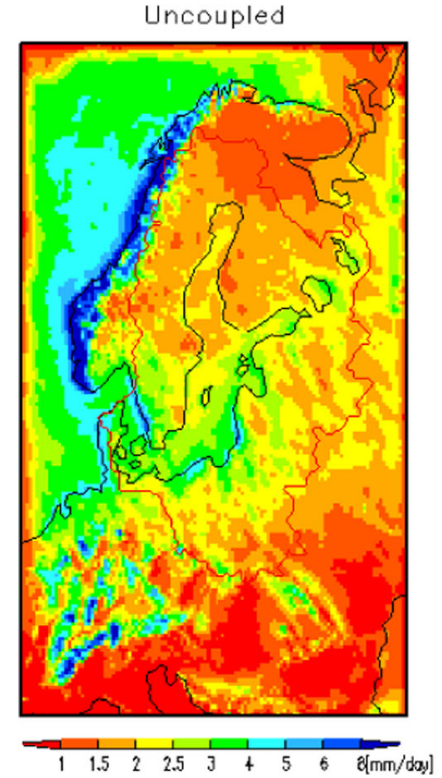

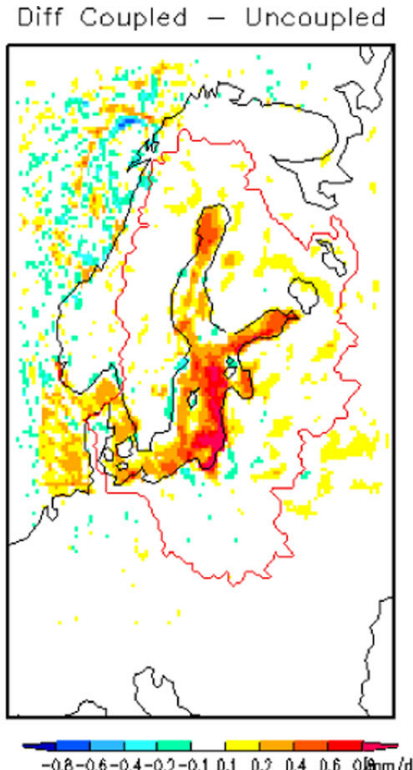


Figure 12 shows as an example for the winter season 2001/2002 the differences between the uncoupled and coupled BALTIMOS simulations. Very similar precipitation amounts were computed for the whole model domain except for the area of the Baltic Sea, where higher surface temperatures are simulated in the coupled experiment (see Fig. 7). These higher temperatures may lead to an increased evaporation, which would increase the atmospheric water vapour content or the precipitable water, which could lead to an intensification of precipitation.

\section{Conclusions}

An integrated regional coupled model system for the Baltic Sea region has been developed and applied for today's climate.

Comparing the simulation results between a coupled and an uncoupled (atmosphere only) simulation shows almost no differences over the land part of the Baltic Sea catchment, and small deviations over the Baltic Sea itself. There is a smaller amplitude in the annual cycle of surface and near-surface temperatures in the coupled experiment, leading to a significantly lower sea ice coverage in this experiment. As this reduced amplitude in temperatures is not realistic, this issue is an unsolved problem in one of the coupled models or in the coupling procedure, which needs further investigations.

The described deviations (like these for SST) in the presented experiments, if not caused by an error within the coupling procedure, could point to shortcomings in the single model components, which are hidden in uncoupled experiments by prescription of boundary values.

As no corrections are applied to the air-sea fluxes in the coupled model system, it should be stressed that there are no obvious trends/drifts visible in the 5 -year integration for today's climate.

When coupling an atmospheric model to an ocean model, both model components have a higher degree of freedom compared to the respective uncoupled model versions: e.g. for the atmospheric model, SST is prescribed and will not change due to erroneous air-sea fluxes. Similar for the uncoupled ocean model, when it is forced at its upper boundary with fluxes calculated from meteorological observations, the input parameter $2-\mathrm{m}$ temperature is prescribed and will stay close to reality even with a wrong modelled surface temperature. If model experiments are forced at their lateral boundaries with analysed data like in the present study, it is therefore an indication for a proper coupling when the coupled model results are close to the uncoupled model results, which are - due to the lower degree of freedom - in most cases closer to the observations. However, if the experiments would be forced by output from a global coupled model system, a possible bias of SST from the global model could be reduced in coupled mode by a more realistic description of the Baltic Sea in the regional ocean model. This would imply deviations between an uncoupled and a coupled experiment, which would be appreciated in this case.

Furthermore, the coupled BALTIMOS system can be used to investigate Baltic Sea inflow events, as it was demonstrated for the winter season 2002/2003 in Lehmann et al. (2004).

Acknowledgments We thank the German Federal Ministry of Education and Research (BMBF) for funding the BALTIMOS project (reference no. 01LD0027). We thank Andreas Lehmann for the ocean/sea ice module, and Karl-Gerd Richter for the hydrological module. We thank the BALTEX Hydrological Data Centre (BHDC) at SMHI for providing the gridded meteorological data set.

\section{References}

Bennartz R, Lorenz P, Jacob D (2009) A comparison of the BALTIMOS coupled climate model with atmospheric and sea surface parameters derived from AMSR-E. Theor Appl Climatol. doi:10.1007/s00704009-0178-X

Bremicker M (2000) Das Wasserhaushaltsmodell LARSIM Modellgrundlagen und Anwendungsbeispiele. Freiburger Schriften zur Hydrologie. Band 11

Döscher R, Willén U, Jones C, Rutgersson A, Meier HEM, Hansson U, Graham LP (2002) The development of the coupled regional oceanatmosphere model RCAO. Boreal Env Res 7:183-192

Forland EJ, Hansson-Bauer I (2000) Increased precipitation in the Norwegian Arctic: true or false? Clim Chang 46:485-509

Haapala J, Leppäranta M (1997) The Baltic Sea ice season in changing climate. Boreal Environ Res 2:93-108

Hagedorn R, Lehmann A, Jacob D (2000) A coupled high resolution atmosphere-ocean model for the BALTEX region. Meteorol Z 9(1): $7-20$

Hagemann S, Machenhauer B, Christensen OB, Déqué M, Jacob D, Jones R, Vidale PL (2002) Intercomparison of regional climate models applied over Europe. Max-Planck-Inst Meteorol, Report Nr. 338

Hennemuth B, Jacob D (2002) One year measurement and simulation of turbulent surface heat fluxes over the BALTIC Sea. Meteorol Z 11(2): 105118

IPCC, Climate Change (2007) Contribution of Working Group I to the Fourth Assessment Report of the Intergovernmental Panel on Climate Change. In: Solomon S, Qin D, Manning M, Chen Z, Marquis M, Averyt KB, Tignor M, Miller HL (eds) The physical science basis. Cambridge University Press, Cambridge, $996 \mathrm{pp}$

Jacob D (2001) A note to the simulation of the annual and interannual variability of the water budget over the Baltic Sea drainage basin. Meteorog Atmos Phys 77:61-73

Jones PD, Moberg A (2003) Hemispheric and large-scale surface air temperature variations: an extensive revision and an update to 2001. J Clim 16:206-223

Lehmann A (1995) A three-dimensional baroclinic eddy-resolving model of the Baltic Sea. Tellus 47A:1013-1031

Lehmann A, Hinrichsen HH (2000) On the thermohaline variability of the Baltic Sea. J Mar Syst 25:333-357

Lehmann A, Krauss W, Hinrichsen HH (2002) Effects of remote and local atmospheric forcing on circulation and upwelling in the Baltic Sea. Tellus 54 A:299-316 
Lehmann A, Lorenz P, Jacob D (2004) Modelling the exceptional Baltic Sea inflow events in 2002-2003. Geophys Res Lett 31:L21308. doi: 10.1029/2004GL020830

Mikolajewicz U, Sein DV, Jacob D, Königk T, Podzun R, Semmler T (2005) Simulating Arctic sea ice variability with a coupled regional atmosphere-ocean-sea ice model. Meteorol Z 14(6):793-800

Omstedt A, Axell L (2003) Modeling the variations of salinity and temperature in the large Gulfs of the Baltic Sea. Cont Shelf Res 23:265-294. doi:10.1016/S0278-4343(02)00207-8

Omstedt A, Meuller L, Nyberg L (1997) Interannual, seasonal and regional variations of precipitation and evaporation over the Baltic Sea. Ambio 26(8):484-492

Omstedt A, Chen Y, Wesslander K (2004) A comparison between the ERA40 and the SMHI gridded meteorological databases as applied to Baltic Sea modelling. Nord Hydrol 36(4-5):369-380
Richter KG, Ebel M (2006) Analysis of runoff for the Baltic basin with an integrated atmospheric-ocean-hydrology model. Adv Geosci 9:31-37

Rinke A, Gerdes R, Dethloff K, Kandlbinder T, Karcher M, Kauker F, Frickenhaus S, Köberle C, Hiller W (2003) A case study of the anomalous Arctic sea ice conditions during 1990: insights from coupled and uncoupled regional climate model simulations. J Geophys Res 108(D9):4275. doi:10.1029/2002JD003146

Rudolph C, Lehmann A (2006) A model measurements comparison of atmospheric forcing and surface fluxes of the Baltic Sea. Oceanologia 48(3):333-360

Rummukainen M, Räisänen J, Bringfelt B, Ullerstig A, Omstedt A, Wille'n U, Hansson U, Jones C (2001) A regional climate model for northern Europe - model description and results from the downscaling of two GCM control simulations. Clim Dyn 17:339-359 